\title{
Effects of sea birds and soil development on plant and soil nutritional parameters after 50 years of succession on Surtsey
}

\author{
RIEN AERTS ${ }^{1}$, RICHARD S.P. VAN LOGTESTIJN ${ }^{1}$, NIKI I.W. LEBLANS ${ }^{2}$ \\ AND BJARNI D. SIGURDSSON ${ }^{3}$ \\ ${ }^{1}$ Dept of Ecological Science, 1081HV Vrije Universiteit Amsterdam, The Netherlands (m.a.p.a.aerts@vu.nl) \\ ${ }^{2}$ Climate Impact Research Centre, Umeå University, Sweden \\ ${ }^{3}$ Agricultural University of Iceland, Hvanneyri 311 Borgarnes, Iceland
}

\begin{abstract}
Surtsey, the island that rose from the sea in a submarine eruption during 1963 to 1967 , has been the subject of many studies on primary succession. These studies have intensified after the establishment of a seagull colony on the island in 1986. This paper reports on the results of a short sampling expedition in 2013 that intended to characterize the interactive effects of the seagull colony and of soil development on soil nutritional characteristics in the tephra sands that cover the underlying lava, as well as in plants growing inside and outside the seagull colony. Feces and pellets of the gulls were extremely rich in both nitrogen $(\mathrm{N})$ and phosphorus $(\mathrm{P})$ and $\delta^{15} \mathrm{~N}$ analyses showed that $\mathrm{N}$ was transferred from pellets and feces to the tephra soils and subsequently taken up by the plants. The tephra soils not affected by the birds showed a high concentration of P compared to $\mathrm{N}$. The concentration of both nutrients was much lower than in the soils of the bird colony. In general, variation in tephra soil depth had little effect on nutritional characteristics, except for the very low $\mathrm{N}$ concentration in deep soils. Thus, our results confirm the overriding effect of the seagull colony on Surtsey on nutritional characteristics of the developing soils and vegetation. Due to the very high P availability of the volcanic soils in combination with the high $\mathrm{P}$ input by the birds, vegetation productivity is $\mathrm{N}$ limited, despite the extremely high $\mathrm{N}$ input of $47 \mathrm{~kg} \mathrm{~N} \mathrm{ha}^{-1} \mathrm{yr}^{-1}$ that the birds add to the system. Our findings emphasize the extreme importance of bird colonies on the nutritional ecology of young, N-poor ecosystems.
\end{abstract}

\section{INTRODUCTION}

Since the submarine eruption that took place during 1963-1967 and its subsequent further development, Surtsey has been the subject of many studies on primary succession, soil development, vegetation development and ecosystem respiration (e.g. Sigurdsson \& Magnusson 2010, Leblans et al. 2014, Magnusson et al. 2014). From these studies, it is clear that both the autonomous soil development and the establishment of a seabird colony has had a great impact on the aforementioned processes. In this context it is important to study plant and soil mineral nutrition as it is critical to our understanding of the functioning of Surtsey ecosystems. It feeds back on photosynthesis, primary production, herbivore forage quality, leaf litter and soil organic matter decomposition and, ultimately, plant-mediated nutrient and carbon cycling pathways and rates (Aerts et al. 2009). Apart from the standard nutritional analyses, the natural abundance of ${ }^{13} \mathrm{C}\left(\delta^{13} \mathrm{C}\right)$ and especially of ${ }^{15} \mathrm{~N}\left(\delta^{15} \mathrm{~N}\right)$ is a good proxy for tracing nutrient transfer in food webs (Bokhorst et al. 2019). In the present study the impact of the presence of a sea bird colony (both through feces and regurgitatad pellets) and of soil development on soil and leaf 
nutritional characteristics were studied by analysing soil- and leaf nutrients and isotopic composition. This was done in a expedition to the island in 2013, after 50 years of primary succession and after 26 years of seagull (Larus sp.) nesting in a confined area on the island. Sampling was performed both inside and outside the seabird colony on the southern part of Surtsey, on shallow soils formed on lava surfaces and on deeper soils formed in tephra (volcanic ash) deposited during the eruption.

\section{MATERIAL AND METHODS}

\section{Study area}

The study was conducted in a series of permanent plots that were already established between 1990 and 1995 (Fig. 1), both inside and outside the permanent breeding colony of seagulls (mainly Larus fuscus L.). In this area many other studies have already taken place (Magnusson et al. 2014). The seagull colony was originally established in 1986 on the south-

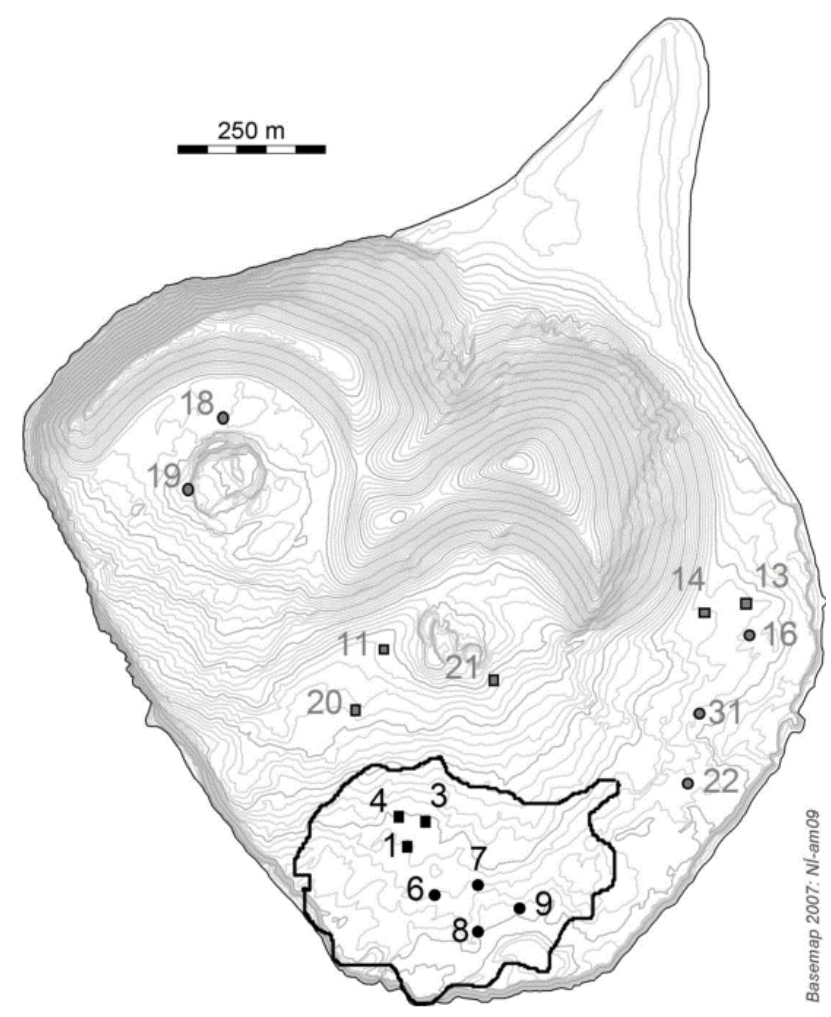

Figure. 1. Location of the permanent study plots on Surtsey that were sampled in the study, shown on a topographical map from 2007. Contour intervals are $2 \mathrm{~m}$, the highest point of the island is $152 \mathrm{~m}$ a.s.l. The sea bird colony plots in the southern part are marked with the solid line and black plot numbers. Outside the colony the plots have grey plot numbers. Circles indicate plots with shallow soils $(<10 \mathrm{~cm}$ soil depth), squares indicate plots with deep soil ( $\geq 30 \mathrm{~cm}$ soil depth).
Table 1. Distribution of the treatments over the plots used in this study (see Fig. 1 for their locations). Shallow: up to $10 \mathrm{~cm}$ deep; Deep: at least $30 \mathrm{~cm}$ deep.

\begin{tabular}{lll}
\hline Treatment & Plotnumbers & $\begin{array}{l}\text { Dominant plant } \\
\text { species }\end{array}$ \\
\hline Shallow, no birds & $16,18,19,22$ & $\begin{array}{l}\text { Leymus arenarius, } \\
\text { Honckenya peploides }\end{array}$ \\
Shallow, + birds & $6,7,9,23$ & $\begin{array}{l}\text { Festuca richardsonii, } \\
\text { Poa } \text { sp., Pucinellia } \\
\text { capillaris } \\
\text { Deep, no birds }\end{array} 11,13,14,20,21$ \\
Leymus arenarius, \\
Honckenya peploides \\
Deep, + birds & $1,3,4$ & $\begin{array}{l}\text { Leymus arenarius, Poa } \\
\text { sp., Stellaria media }\end{array}$ \\
\hline
\end{tabular}

western part of the island and by time it has grown in size as the number of birds has increased (Fig. 1). The study was conducted in plots with shallow soils $(\leq 10$ $\mathrm{cm}$ soil) formed by wind-borne tephra sands that had covered the basaltic lava surfaces and in deep soils ( $>$ $30 \mathrm{~cm}$ soil) in areas where the tephra sands had been deposited during the eruption (see Leblans et al. 2014 for further details). The vegetation on the sandy areas outside the colony was dominated by Honckenya peploides (L.) Ehrh. and Leymus arenarius (L.) Hochst. The dominant plant species inside the seagull colony were Poa pratensis L., P. annua L., Festuca richardsonii (Hook.) Hultén., with some Leymus arenarius and Stellaria media (L.) Vill. in the deeper soils (Table 1).

\section{Sampling}

In July 2013, when the biomass was at its maximum, the sampling was carried out according to the twofactorial design (soil depth and bird presence) as described above. To characterize the nutritional composition of the sea bird input to the ecosystem, we collected sea gull feces and pellets. Additionally, we took a sample of mature leaves from a representative species mix in each plot (see Table 1) and a soil sample down to a standard depth of $15 \mathrm{~cm}$ in each plot (deep soils) or to the depth that the underlying lava allowed (shallow soils). The samples were airdried in Surtsey and after the expedition transported to Amsterdam, where they were dried at $70{ }^{\circ} \mathrm{C}$ for further analysis.

\section{Chemical analyses}

After drying, the samples were ground for chemical analyses. The $\mathrm{C}$ and $\mathrm{N}$ concentration and the $\delta^{13} \mathrm{C}$ 
and $\delta^{15} \mathrm{~N}$ signature of each sample was quantified by dry combustion in an NC 2500 elemental analyzer (Carlo Erba, Rodana, Italy) coupled with a Delta ${ }^{\text {plus }}$ continuous-flow isotope ratio mass spectrometer (Thermo Finnigan, Bremen, Germany). The isotopic ratios were converted to delta units $(\delta)$ in parts per thousand, according to the formula:

$$
\delta(\%)=\left(\mathrm{R}_{\text {sample }} / \mathrm{R}_{\text {standard }}-1\right) * 1000
$$

in which $\mathrm{R}$ is the molar ratio of heavy to light isotopes $\left({ }^{13} \mathrm{C} /{ }^{12} \mathrm{C}\right.$ or $\left.{ }^{15} \mathrm{~N} /{ }^{14} \mathrm{~N}\right)$. The $\mathrm{R}_{\text {standard }}$ for $\mathrm{C}$ was VPDB and for $\mathrm{N}$ it was the ratio for atmospheric $\mathrm{N}_{2}$ (air).

Leaf $\mathrm{P}$ and soil $\mathrm{P}$ concentrations were determined by digesting ground leaf material in $37 \% \mathrm{HCl}$ : $65 \% \mathrm{HNO}_{3}(1: 4, \mathrm{v} / \mathrm{v})$. Phosphorus was measured colorimetrically at $880 \mathrm{~nm}$ after reaction with molybdenum blue.

\section{RESULTS AND DISCUSSION}

Both the gull feces and pellets had extremely high concentrations of $\mathrm{N}$ and, especially, of $\mathrm{P}$. This resulted in very low $\mathrm{C} / \mathrm{N}$ ratios and an extremely low N/P ratio (Table 1). There were no significant differences between feces and pellets for any of the nutritional parameters. The nutrient ratios observed are far below the lowest values reported for both living and dead leaves (Aerts \& Chapin 2000), but are characteristic for bird excrements (Bokhorst et al. 2019). This implies that input of gull feces and pellets into soils results in a different ratio of $\mathrm{N}$ to $\mathrm{P}$ input compared to the input of leaf litter.

As is usually found for soils with low carbon content soil $\mathrm{N}$ and $\mathrm{P}$ concentrations were relatively low. However, higher soil $\mathrm{N}$ and $\mathrm{P}$ concentrations were found inside than outside the seagull colony (Tables 2 and 3). The $\mathrm{N}$ concentration of the shallow soil in the colony was higher than in the deeper soil, where it was extremely low. This is probably due to the fact that most of the $\mathrm{N}$ is concentrated in the top layer. Therefore the $\mathrm{N}$ is more "diluted" in a deeper soil. The dilution can even have been underestimated in the present study, as we did not sample the whole tephra soil profile in the deep soils. Stefansdottir et al. (2014) sampled tephra soil profiles down to $80 \mathrm{~cm}$. They found that considerable amounts of accumulated SOC and N were found below $15 \mathrm{~cm}$ depth where the deep-rooted Honckenya peploides and Leymus arenarius were growing.

The $\mathrm{C} / \mathrm{N}$ ratios in the soil were not affected by bird presence or soil depth. This was in contrast with the $\mathrm{N} / \mathrm{P}$ ratios where bird presence led to higher ratios. Higher N/P ratios were also found in the shallow soils compared to the deep soils (Tables 2, 3). As clearly shown by the extremely low soil N/P ratios outside the bird colony, these young volcanic soils are very rich in $\mathrm{P}$ compared to $\mathrm{N}$. This is a general characteristic of volcanic soils (Arnalds 2015).

In southern Iceland, Edlinger (2016) found that $\delta^{15} \mathrm{~N}$ values in bulk soil $(0-10 \mathrm{~cm})$ varied between 0.3 to 1.3 in developed, dryland volcanic (Brown Andosol) soil and in grasses the $\delta^{15} \mathrm{~N}$ value varied between 1.0 to 1.8 at the same site (unpublished). The plant $\delta^{15} \mathrm{~N}$ values outside the seagull colony in Surtsey were in the same range (Table 2).

It is striking to see that the $\delta^{15} \mathrm{~N}$ isotopic signatures of the gull feces and pellets were clearly reflected in the soil signatures in the gull colony (Table 2). On average the soil $\delta^{15} \mathrm{~N}$ was 12.9 in the soil and 13.2 in the feces and pellets (Table 2). Unfortunately, these signatures could not be determined for all the soils outside the colony due to the extremely low $\mathrm{N}$ and $\mathrm{C}$ concentrations. They were below the detection limit for the continuous-flow isotope ratio mass spectrometer.

The vegetation in the gull colonly had a substantially higher $\delta^{15} \mathrm{~N}$ value than the vegetation in the shallow soils outside the colony. The plant $\delta^{15} \mathrm{~N}$ was on average 17.9 within the gull colony (Table 2), i.e. much closer to the high values found in gull feces and pellets $\left(\delta^{15} \mathrm{~N}\right.$ of 13.0) and to the soil in the colony $\left(\delta^{15} \mathrm{~N}\right.$ of 12.9 ; Table 2$)$ or from normal soil and plant $\delta^{15} \mathrm{~N}$ values in Icelandic grasslands (Edlinger 2016). This strongly supports that the $\mathrm{N}$ accumulation seen within the seagull colony is largely derived from the feces and pellets, and does not result from more effective $\mathrm{N}$ retention of $\mathrm{N}$-deposition by the more vegetated soils or by $\mathrm{N}$-fixation.

The $\delta^{15} \mathrm{~N}$ value was significantly higher in plants on deep than shallow soils, both within and outside the seagull colony (Tables 2, 3). In the deep soils within the gull colony the the $\delta^{15} \mathrm{~N}$ value was even substantially higher than in feces and pellets ( $21.5 \mathrm{vs}$. 13.2, respectively; Table 2). The natural abundance of ${ }^{15} \mathrm{~N}$ in leaves provides a measure of mineral nutrition that reflects differences in a number of properties and processes, such as the forms of $\mathrm{N}$ source (Michelsen et al. 1996, Robinson 2001), the type of mycorrhizal infection (Michelsen et al. 1998) and differences in signatures among soil layers (Robinson 2001). This 
Table 2. Nutritional data of gull feces and pellets, soils and plants at Surtsey inside (+birds) and outside (-birds) the gull colony and for deep and shallow soils. Shallow: up to $10 \mathrm{~cm}$ deep; Deep: at least $30 \mathrm{~cm}$ deep. bdl: below detection limits.

\begin{tabular}{|c|c|c|c|c|c|c|c|}
\hline & $\% \mathbf{N}$ & $\% \mathrm{P}$ & $\% \mathrm{C}$ & $\mathrm{C} / \mathrm{N}$ ratio & $\mathrm{N} / \mathrm{P}$ ratio & $\delta 15 \mathrm{~N}(\%)$ & $\delta 13 C(\%)$ \\
\hline \multicolumn{8}{|c|}{ Gull feces $(n=2)$} \\
\hline Mean & 8.93 & 6.22 & 26.03 & 2.89 & 1.47 & 13.15 & -18.79 \\
\hline SD & 0.33 & 1.16 & 11.25 & 1.15 & 0.33 & 2.52 & 2.75 \\
\hline \multicolumn{8}{|c|}{ Gull pellets $(n=2)$} \\
\hline Mean & 7.93 & 6.51 & 26.47 & 3.37 & 1.23 & 13.31 & -18.18 \\
\hline $\mathrm{SD}$ & 1.77 & 0.29 & 3.63 & 0.30 & 0.33 & 0.70 & 1.71 \\
\hline \multicolumn{8}{|c|}{ Soil, +birds, deep (n=3) } \\
\hline Mean & 0.15 & 0.13 & 1.91 & 13.36 & 1.10 & 13.99 & -28.41 \\
\hline SD & 0.07 & 0.03 & 0.80 & 1.57 & 0.46 & 0.93 & 0.67 \\
\hline \multicolumn{8}{|c|}{ Soil, +birds, shallow $(n=4)$} \\
\hline Mean & 0.57 & 0.11 & 8.66 & 14.76 & 5.54 & 11.69 & -27.54 \\
\hline SD & 0.39 & 0.02 & 6.58 & 1.35 & 4.54 & 4.86 & 1.18 \\
\hline \multicolumn{8}{|c|}{ Soil, -birds, deep $(n=5)$} \\
\hline Mean & 0.01 & 0.10 & 0.10 & 13.36 & 0.08 & bdl & bdl \\
\hline SD & 0.00 & 0.01 & 0.02 & 0.69 & 0.02 & & \\
\hline \multicolumn{8}{|c|}{ Soil, -birds, shallow $(\mathrm{n}=4)$} \\
\hline Mean & 0.01 & 0.10 & 0.13 & 11.94 & 0.13 & bdl & bdl \\
\hline SD & 0.01 & 0.01 & 0.06 & 2.25 & 0.09 & & \\
\hline \multicolumn{8}{|c|}{ Vegetation, +birds, deep $(\mathrm{n}=3)$} \\
\hline Mean & 2.44 & 0.49 & 45.42 & 18.67 & 5.00 & 21.51 & -27.65 \\
\hline SD & 0.23 & 0.02 & 0.93 & 2.04 & 0.65 & 0.77 & 0.29 \\
\hline \multicolumn{8}{|c|}{ Vegetation, +birds, shallow $(n=4)$} \\
\hline Mean & 2.47 & 0.49 & 44.88 & 19.98 & 5.48 & 14.81 & -29.60 \\
\hline SD & 0.17 & 0.16 & 1.73 & 2.75 & 2.69 & 3.69 & 1.12 \\
\hline \multicolumn{8}{|c|}{ Vegetation, -birds, deep $(n=5)$} \\
\hline Mean & 2.06 & 0.18 & 42.52 & 21.09 & 12.55 & 1.81 & -27.82 \\
\hline SD & 0.16 & 0.04 & 4.34 & 0.22 & 1.57 & 2.56 & 0.48 \\
\hline \multicolumn{8}{|c|}{ Vegetation, -birds, shallow $(\mathrm{n}=4)$} \\
\hline Mean & 2.18 & 0.15 & 40.91 & 19.30 & 16.23 & 0.70 & -27.76 \\
\hline SD & 0.05 & 0.02 & 0.46 & 0.91 & 4.71 & 2.23 & 0.81 \\
\hline
\end{tabular}

makes it hard to interpret the change in the leaf $\delta^{15} \mathrm{~N}$ values between deep and shallow soils as so many processes are involved. The data presented here do suggest that, given the differences among deep and shallow soils, that the plants in the deep soils are able to tap nitrogen from deeper layers, although the amount of $\mathrm{N}$ there is very low.

The $\delta^{13} \mathrm{C}$ signatures in soils and vegetation were relatively constant with values around $-28 \%$. This is in line with the values normally found in soil organic matter and plant material of C3 plants (Farquhar et al. 1989) and also in Icelandic grassland soils (Edlinger 2016). The $\delta^{13} \mathrm{C}$ signatures in the gull feces and pellets are clearly less negative, but in contrast with ${ }^{15} \mathrm{~N}$, there is no physiological connection between the ${ }^{13} \mathrm{C}$ in these compounds and that in soil organic matter and in plants. These signatures are largely determined by carbon fixation and $\mathrm{CO}_{2}$ diffusion through the stomata (Buchmann et al. 1997, Alstad et al. 1999). Some direct effect on soil $\delta^{13} \mathrm{C}$ signatures could occur from feces and pellet inputs if those would accumulate as 'guano' in the organic layer of the soil. Leblans (2016), however, addressed this and estimated that the direct C-input from the seabirds could only account for a few percentage of the observed SOC accumulation within the seabird colony and such direct effects should therefore be minimal.

Plant $\mathrm{N}$ concentrations (determined on the mix of species present) were higher inside than outside the colony, but the effect was relatively small (Tables 2, 3). This contrasts sharply with the plant $\mathrm{P}$ concentrations, as they were about 3 times higher within than outside the colony. As a result, the N/P ratios of plants inside the colony were around 5 , which points to strong $\mathrm{N}$ limitation (Aerts \& Chapin 2000). Outside the colony the N/P ratio was, on the other hand, between 12.5 (deep soils) and 16.2 (shallow soils) which is close to $P$ limitation, as a N/P ratio $>16$ indicates $\mathrm{P}$ limited plant 
Table 3. Results of 2-way analyses of variance on various nutritional parameters in soil and vegetation with soil depth and bird presence as independent parameters. $* \mathrm{P}$ $<0.05, * * \mathrm{P}<0.01, * * * \mathrm{P}<0.001$, N.S.: non-significant; bdl: below detection limits.

\begin{tabular}{cllll}
\hline & & Bird presence & Soil depth & Interaction \\
\hline Soil & & & & \\
& $0 \mathrm{~N}$ & $* * *$ & $*$ & $*$ \\
$\% \mathrm{P}$ & $*$ & $\mathrm{~N} . \mathrm{S}$. & $\mathrm{N} . \mathrm{S}$. \\
$\% \mathrm{C}$ & $* * *$ & $* *$ & $\mathrm{~N} . \mathrm{S}$. \\
$\mathrm{C} / \mathrm{N}$ ratio & $\mathrm{N} . \mathrm{S}$. & $\mathrm{N} . \mathrm{S}$. & $*$ \\
$\mathrm{~N} / \mathrm{P}$ ratio & $* * *$ & $*$ & N.S. \\
$\delta 15 \mathrm{~N}$ & bdl & & \\
$\delta 13 \mathrm{C}$ & bdl & & \\
Vegetation & & & \\
$\% \mathrm{~N}$ & $*$ & $*$ & N.S. \\
$\% \mathrm{P}$ & $* * *$ & N.S. & N.S. \\
$\% \mathrm{C}$ & $\mathrm{N} . \mathrm{S}$. & N.S. & N.S. \\
$\mathrm{C} / \mathrm{N}$ ratio & N.S. & N.S. & N.S. \\
$\mathrm{N} / \mathrm{P}$ ratio & $* * *$ & N.S. & N.S. \\
$\delta 15 \mathrm{~N}$ & $* * *$ & $* *$ & N.S. \\
$\delta 13 \mathrm{C}$ & $\mathrm{N} . \mathrm{S}$. & $*$ & $*$ \\
\hline
\end{tabular}

growth (Aerts \& Chapin 2000). Soil depth had hardly any effect on these nutritional parameters. One other study has addressed the $P$ availability inside and outside the seagull colony in Surtsey, by looking at the N/P ratios of the same plant species (Cerastium fontanum (Hartm.) Greuter \& Burdet) growing both inside and outside the colony (Leblans et al. 2017). Surprisingly, they found the reverse; the plant N/P ratio was lower outside the seagull colony (ca. 6) compared to inside the colony (ca. 10). The $\mathrm{P}$ cycle reserves therefore a further study on Surtsey.

The relative low effect of gulls on the leaf $\mathrm{N}$ concentration inside the seagull colony is probably caused by the about 70 times higher carbon stock inside the colony than outside it, whereas the $\mathrm{N}$ stock is "only" 30 times higher (data from Leblans et al. 2014). This strongly suggests that the higher $\mathrm{N}$ accumulation rate in the colony than outside (47 vs $0.7 \mathrm{~kg} \mathrm{~N} \mathrm{ha}^{-1} \mathrm{yr}^{-1}$ ) is translated into a much higher biomass production, and hence $\mathrm{N}$ uptake from soil, which results in only a minor increase in leaf $\mathrm{N}$ concentration despite the about 70 times higher $\mathrm{N}$ input.

In conclusion, in line with other studies, the present study shows the overriding effect of the seagull colony at Surtsey on nutritional characteristics of the soils and vegetation on the island. Due to the very high $\mathrm{P}$ richness of the volcanic soils in combination with the high $\mathrm{P}$ input by the birds, vegetation productivity is $\mathrm{N}$ limited, despite the extremely high $\mathrm{N}$ input of $47 \mathrm{~kg}$ $\mathrm{N} \mathrm{ha}^{-1} \mathrm{yr}^{-1}$ they produce. However, further studies are needed on $\mathrm{P}$ availability for plants outside the seagull colony, and on whether low P availability (relative to $\mathrm{N}$ ) can possibly be a co-limiting factor for plant productivity there.

\section{ACKNOWLEDGEMENTS}

The authors would like to thank Dr Borgpór Magnússon, Icelandic Institute of Natural History, for coordinating the Surtsey excursion in 2013 and the Surtsey Research Society for permitting this study and for logistic support. We further thank the Icelandic Coast Guard for the adventurous helicopter transport to and from the island.

\section{REFERENCES}

Aerts, R. \& F.S. Chapin, 2000. The mineral nutrition of plants revisited: A re-evaluation of patterns and processes. Advances in Ecological Research 30, 1-67.

Aerts, R., T.V. Callaghan, E. Dorrepaal, R.S.P. van Logtestijn \& J.H.C. Cornelissen, 2009. Seasonal climate manipulations result in species-specific changes in leaf nutrient levels and isotopic composition in a sub-arctic bog. Funct. Ecol. 23, 680688.

Alstad, K.P., J.M. Welker, S.A. Williams \& M.J. Trilica, 1999. Carbon and water relations of Salix monticola in response to winter browsing and changes in surface water hydrology: an isotopic study using delta C-13 and delta O-18. Oecologia 120, 375-385.

Arnalds, O., 2015. The soils of Iceland. Springer, Netherlands.

Bokhorst, S.F., P. Convey \& R. Aerts, 2019. Nitrogen Inputs by Marine Vertebrates Drive Abundance and Richness in Antarctic Terrestrial Ecosystems. Current Biology 29, 1721-1729.

Buchmann, N., W.-Y. Kao \& J. Ehleringer, 1997. Influence of stand structure on carbon-13 of vegetation, soils, and canopy air within deciduous and evergreen forests in Utah, United States. Oecologia 110, 109-119.

Edlinger, A.T. 2016. Changes of belowground processes of the carbon and nitrogen cycle in response to soil warming. Will global warming increase the turnover of soil $\mathrm{C}$ and $\mathrm{N}$ above plant demands and lead to increased leaching losses? (M.Sc. thesis) Dept. of Geosciences and Natural Resource Management 66 p. Copenhagen University, Denmark \& University of Natural Resources and Applied Sciences (BOKU), Austria, Copenhagen, Denmark

Farquhar, G.D., J.R. Ehleringer \& K. Hubick, 1989. Carbon isotope discrimination and photosynthesis. Ann. Rev. Plant Physiol. Plant Mol. Biol. 40, 503-537. 
Leblans N.I.W., 2016. Natural gradients in temperature and nitrogen: Iceland represents a unique environment to clarify longterm global change effects on carbon dynamics. (PhD thesis). 229 p. Joint thesis between Agricultural University of Iceland and University of Antwerp, Reykjavik, Iceland

Leblans, N.I.W., B.D. Sigurdsson, P. Roefs, R. Thuys, B. Magnusson \& I.A. Janssens, 2014. Effects of seabird nitrogen input on biomass and carbon accumulation after 50 years of primary succession on a young volcanic island, Surtsey. Biogeosciences 11, 6237-6250.

Leblans, N.I.W., B.D. Sigurdsson, R. Aerts, S. Vicca, B. Magnússon \& I.A. Janssens, 2017. Icelandic grasslands as long-term $\mathrm{C}$ sinks under elevated organic $\mathrm{N}$ inputs. Biogeochemistry 134, 279-299.

Magnússon B., S.H. Magnússon, E. Ólafsson \& B.D. Sigurdsson, 2014. Plant colonization, succession and ecosystem development on Surtsey with reference to neighbour islands. Biogeosciences 11, 5521-5537.

Michelsen, A., I.K. Schmidt, S. Jonasson, C. Quarmby \& D. Sleep, 1996. Leaf ${ }^{15} \mathrm{~N}$ abundance of subarctic plants provides field evidence that ericoid, ectomycorrhizal and non- and arbuscular mycorrhizal species access different sources of soil nitrogen. Oecologia 105, 53-63.

Michelsen A., C. Quarmby, D. Sleep \& S. Jonasson, 1998. Vascular plant ${ }^{15} \mathrm{~N}$ natural abundance in heath and forest tundra ecosystems is closely correlated with presence and type of mycorrhiza in roots. Oecologia 115, 406-418.

Robinson, D., 2001. $\delta 15 \mathrm{~N}$ as an integrator of the nitrogen cycle. Trends Ecol. Evol. 16, 153-162.

Sigurdsson, B.D. \& G. Stefánsdóttir, 2015. Ecosystem $\mathrm{CO}_{2}$ flux rates in relaton to vegetation type and age of Leymus arenarius dunes on Surtsey. Surtsey Research 13, 9-15.

Sigurdsson, B.D., \& B. Magnusson, 2010. Ecosystem respiration, vegetation development and soil nitrogen in relation to breeding density of seagulls on a pristine volcanic island, Surtsey, Iceland. Biogeosciences 7, 883-891.

Stefansdottir, G., A.L. Aradottir \& B.D. Sigurdsson, 2014. Accumulation of nitrogen and organic matter during primary succession of Leymus arenarius dunes on the volcanic island Surtsey, Iceland. Biogeosciences 11, 5763-5771. 